\title{
Vertical root fracture resistance and crack formation of root canal-treated teeth restored with different post-luting systems
}

Andreas Rathke ( $\square$ Andreas.Koushan-Rathke@dentsplysirona.com )

University of Ulm: Universitat Ulm https://orcid.org/0000-0003-1012-1191

Henry Frehse

University of Ulm: Universitat Ulm

Beatrice Hrusa

Private practice

\section{Research Article}

Keywords: Dentin crack, Fiber-reinforced composite, Post, Staircase, Vertical root fracture

Posted Date: January 24th, 2022

DOI: https://doi.org/10.21203/rs.3.rs-1213548/v1

License: (c) (1) This work is licensed under a Creative Commons Attribution 4.0 International License.

Read Full License 


\section{Abstract}

To investigate the vertical root fracture (VRF) resistance and crack formation of root canal-treated teeth restored with different post-luting systems. Human maxillary lateral incisors of similar size were decoronated, assigned to five groups $(n=18$, power $=0.9)$ and embedded in acrylic blocks with artificial periodontium. After root canal filling, post spaces were prepared and coated fiber-reinforced composite (FRC) or sandblasted titanium (TIT) posts of the same shape and size were placed. Half of the posts were zinc phosphate cemented (C), while the other half was adhesively luted (A). Untreated teeth served as control. After thermal cycling and staircase loading in a chewing simulator, the crack formation on the root dentin surface was microscopically examined and classified as no defect, craze line, vertical crack, and horizontal crack. Subsequently, the samples were loaded until root fracture. Data were analyzed by one-way ANOVA, Tukey's test, and Fisher's exact test. All samples survived the chewing simulation without VRF, but crack formation was significantly different between the groups $(P=0.009)$. The control showed significantly fewer defects than FRC/C, TIT/C, and TIT/A $(P=0.001, P=0.008, P=0.008$, respectively). $\mathrm{FRC/C}$ showed the highest incidence of vertical cracks. $\mathrm{FRC/A}$ had the lowest incidence of defects. There was no significant difference in VRF resistance between the groups $(P=0.265)$. Adhesively luted FRC posts did not increase VRF resistance but reduced the risk of defects. Most defects were craze lines and vertical root cracks.

\section{Introduction}

Vertical root fractures (VRF) are serious adverse events that often result in the extraction of the tooth. Although a low prevalence of VRF is reported in the literature [1], other investigations showed a risk of up to $34.7 \%$ [2]. The VRF prevalence was significantly higher when a post was placed than in root canaltreated teeth without post [3]. Root canal treatment and post space preparation can damage the root dentin and lead to incomplete cracks or craze lines that can develop into VRF [4-6]. Research agrees that root canal-treated teeth cannot be reinforced with cemented metal posts and adhesively luted fiberreinforced composite (FRC) posts are a promising technique for reinforcing teeth [7-10]. FRC posts have a superior stress distribution due to their dentin-like Young's modulus and adhesion to root dentin $[7,11]$. Their potential to reduce the incidence of irreparable root fractures $[7,11]$ and to result in higher survival rates than metal posts was highlighted [12]. However, other studies found that FRC posts do not reinforce teeth $[13,14]$ and that both the prevalence of irreparable root fracture and the survival rate are comparable to that of metal posts [15]. The only long-term study to date showed a significantly higher survival rate for adhesively luted titanium posts than for adhesively luted FRC posts after 11 years [16]. However, the approximate $50 \%$ drop-out rate and the lack of power of the study did not allow sufficient evidence for the selection of FRC versus titanium posts [17]. Since the results are inconclusive so far, the most suitable post concept remains controversial.

Three-dimensional finite element analyses (3D-FEM) indicated that the favorable stress distribution of FRC posts can lose its impact over time if the adhesion to the root dentin fails and higher stress are concentrated in the root $[18,19]$. Cracks were initiated when the concentrated stress exceeded the tensile 
strength of the root dentin. It has been demonstrated that cracks can propagate under repeating subcritical loads and lead to future fractures [20]. However, studies usually addressed the fracture resistance and location of the fracture under static loading $[11,21]$. Some authors focused on postrestored teeth under fatigue loading $[6,10,14,22]$. One reason is that the number of cycles until fracture is very high under physiological chewing loads. Alternatively, staircase loading with gradually increasing load for a certain number of cycles was used for fatigue testing of post-restored teeth [10]. The aim of this study was to evaluate the influence of cemented and adhesively luted FRC or titanium posts on resistance against VRF and dentin defects after chewing simulation. The first hypothesis to be tested was that the VRF resistance is not significantly different between the groups. The second null hypothesis was that there is no significant difference in the incidence of defects between the groups.

\section{Materials And Methods}

\section{Sample size calculation}

The sample size was calculated using unpublished pilot data $(n=5)$ and the two-sided Welch's t-test for unequal variance at a significance level of $P \leq 0.05$ and a power of 0.9 (nQuery Advisor version 7 , Statistical Solutions, Cork, Ireland). The sample size was evaluated as $n=15$ for each group. Considering some dropouts and a deviation of normality assumptions a sample size of $n=18$ was used in the study.

\section{Sample preparation}

Extracted human maxillary lateral incisors with comparable dimensions were disinfected in accordance with the university's policy. The teeth were cleaned with scalers and stored in $1 \%$ chloramine trihydrate solution. Crowns were removed using a diamond saw at slow speed (WOCO 50/Med, Conrad, ClausthalZellerfeld, Germany) to obtain roots of $13 \mathrm{~mm}$ length. A stereomicroscope (Stemi SV8, Zeiss, Oberkochen, Germany) at $12 \times$ magnification was used to exclude any pre-existing dentin defects. After numbering the teeth, the cross sections of the roots were measured at the level of the cutting surface in the mesio-distal and bucco-palatal direction with a digital caliper (Garant, Hoffmann, Munich, Germany). The area of the ellipsed root cross section (A) was calculated according to: $A=p / 4 \times a \times b$ (where $a$ and $b$ were the mesiodistal and bucco-palatal dimension in $\mathrm{mm}$ ). Roots of extreme size were excluded. The remaining samples were randomly distributed into five groups of 18 roots each according to a random numbers table. To imitate a human periodontium with uniform stress distribution, the roots were wrapped in one layer of latex rubber milk (Suter Kunststoffe, Jegenstorf, Switzerland) with a thickness of approximately $250 \mu \mathrm{m}$ and embedded in acrylic resin (Technovit 4071, Heraeus Kulzer, Hanau, Germany) with the coronal third (4 $\mathrm{mm}$ ) being exposed.

In the control group, the roots were left untreated. In the other groups, the canals were instrumented using single-length technique with nickel-titanium rotary files (EasyShape, Brasseler Komet, Lemgo, Germany) up to file size 40 and 0.04 taper. The working length was set to $12 \mathrm{~mm}$. During instrumentation, canals were irrigated with $5 \mathrm{ml}$ of $3 \%$ sodium hypochlorite $(\mathrm{NaOCl})$ and $15 \%$ ethylenediaminetetraacetic acid (EDTA) solutions (Glyde File Prep, Dentsply Sirona, Ballaigues, Switzerland). After a flush with $5 \mathrm{ml}$ 
distilled water, the canals were dried with paper points and obturated with the matched EasyShape gutta percha cone and EasySeal resin-based sealer (Brasseler Komet) using the single-cone technique.

\section{Post placement}

Drills supplied by the post manufacturer (Brasseler Komet) were used to prepare post spaces of $8 \mathrm{~mm}$ depth and size ISO 70. Gutta percha was removed with the pilot drill 183LB leaving $4 \mathrm{~mm}$ of the root filling in the apical portion. The root canals were enlarged with the reamer 196 and roughened with the form congruent diamond instrument 196D. After a flush with $5 \mathrm{ml}$ distilled water, the post spaces were dried with paper points. Coated FRC posts (ER DentinPost Coated) and sandblasted titanium posts (ER Kopf-Stift) (TIT) in the same cylindroconical shape and size (ISO 70) were shortened from the coronal end to $7 \mathrm{~mm}$ with diamond drills under water cooling so that they could be placed into the post canals 1 $\mathrm{mm}$ below the cutting surface of each root. All posts were cleaned with $70 \%$ alcohol. For each post material, half of the samples were cemented (C), while the other half was adhesively luted (A). For cementation, zinc phosphate (Richter \& Hoffmann, Berlin, Germany) was mixed in a creamy consistency in relation $1.5 \mathrm{~g}$ zinc oxide powder to $1 \mathrm{~g}$ phosphoric acid on a cooled glass plate and applied to the post surface. After post insertion, excess cement material was removed with brushs. For adhesive luting, the dual-curing luting system of the posts were applied following manufacturer's instructions. Post spaces were etched for $20 \mathrm{~s}$ with $37 \%$ phosphoric acid gel, rinsed with water spray, and dried with paper points. The etch-and-rinse adhesive DentinBond was applied to the root dentin and light-cured for $10 \mathrm{~s}$. The composite DentinBuild was applied to the post surface directly from the automixing syringe. After post insertion, excess composite was removed with brushs. Light curing was performed for $20 \mathrm{~s}$ at 1000 $\mathrm{mW} / \mathrm{cm}^{2}$ light intensity (Astralis 10, Ivoclar Vivadent, Schaan, Liechtenstein). The cervical $1 \mathrm{~mm}$ of the post space was temporarily filled (Cavit, 3M Espe, Seefeld, Germany).

\section{Chewing simulation and VRF testing}

After water storage for $24 \mathrm{~h}$ at $37^{\circ} \mathrm{C}$, the samples were subjected to 1500 thermocycles in distilled water at $5-55^{\circ} \mathrm{C}$ with a dwelling time of $20 \mathrm{~s}$ in each bath (Haake W15, Willytec, Gräfelfing, Germany). Mechanical loading was performed according to the staircase method starting at a load of $25 \mathrm{~N}$ at an angle of $10^{\circ}$ to the axial direction of the roots in a chewing simulator (Standard 2002, Willytec). Every 20,000 cycles at a frequency of $2 \mathrm{~Hz}$, the load was increased in increments of $25 \mathrm{~N}$ until 120,000 cycles were reached. The unfilled cervical $1 \mathrm{~mm}$ of the post space ensured that the force applied by the coneshaped metal antagonist with an angle of $90^{\circ}$ was transmitted to the root dentin rather than the post. The diameter of the truncated cone was dimensioned in such a way that the cone tip fitted exactly into the coronal unfilled post space.

After chewing simulation, the external root surfaces were examined under the microscope using a cold light source (Stemi SV8, Zeiss). Because of the latex milk, the roots could easily be removed from the acrylic blocks. Pictures were taken with a digital camera at 12-100 x magnification (3CCD Color Video Camera, Sony, Tokyo, Japan). Crack formation was analyzed per root section (cervical, middle, apical) as 
follows: (a) no defect, (b) craze line, (c) vertical crack, and (d) horizontal crack. Representative images of the dentin defects are shown in Figure 1. After microscopic analysis, the roots were returned to the acrylic blocks and subjected to VRF testing. The same antagonist as used for the chewing simulator was attached to the load cell of a universal testing machine (Zwicki 1120, Zwick, Ulm, Germany). The samples were loaded until fracture with a crosshead speed of $1 \mathrm{~mm} / \mathrm{min}$. The fracture load $(\mathrm{N})$ was recorded when the force in the load-strain curve decreased by $30 \%$.

\section{Statistics}

Statistical analysis was performed with IBM SPSS version 19 for Windows (Chicago, IL, USA). The significance level was set in advance at $P \leq 0.05$. Differences in crack formation were evaluated by Fisher's exact test. After confirming that the VRF resistance $(P=0.244)$ and the root cross sectional area $(P=0.651)$ met the assumptions of normality as indicated by the Kolmogorov-Smirnov test, differences between the means of the groups were compared with one-way ANOVA followed by post hoc Tukey's test.

\section{Results}

The mean values for the VRF resistance, the mean cross-sectional area, and the crack formation are shown in Table 1. All samples survived the chewing simulation without a complete root fracture. The incidence of dentin defects was significantly different between the groups $(P=0.009)$. The control teeth showed significantly fewer defects than the post-luting groups $\mathrm{FRC} / \mathrm{C}(P=0.001)$, TIT/C $(P=0.008)$, and TIT/A $(P=0.008)$. FRC/C showed the highest incidence of defects, mainly vertical cracks. FRC/A showed the lowest incidence of defects that was not significantly different from that of the control teeth $(P=$ 0.153). Among the post-luting groups, $44 \%$ of the samples showed dentin defects in the apical root third, while $66 \%$ and $72 \%$ of the samples had dentin defects in the cervical and middle root section, respectively.

No significant differences were found between the groups regarding VRF resistance $(P=0.265)$ and cross-sectional area $(P=0.402)$. The cemented FRC post group showed the lowest resistance to cause VRF $(748 \pm 239 \mathrm{~N})$, while the cemented titanium post group had the highest VRF resistance $(921 \pm 328$ $\mathrm{N})$.

\section{Discussion}

The data support acceptance of the first null hypothesis, because the results did not show significant differences in VRF resistance. After chewing simulation, none of the roots were completely fractured and the VRF resistance did not differ significantly between adhesively luted posts and their counterparts in the zinc phosphate cement group. Several studies highlighted the challenges of adhesive luting of posts. Factors such as an unfavorable configuration factor, high polymerization shrinkage, interfacial gaps around the post, and difficulties in polymerization inside the post space can negatively influence the 
adhesive post luting $[10,22,23]$. Therefore, in this study, particular attention was given to the bonding procedure through dentin roughening of the post space, industrial silica and silane coating of the FRC post surface (average roughness $R_{a} \sim 3 \mu \mathrm{m}$ ) [24], industrial sandblasting with aluminum oxide of the titanium post surface $\left(R_{a} \sim 12 \mu \mathrm{m}\right)$ [25], and the use of the corresponding dual-curing luting system of the post manufacturer $[7,25]$. Surface roughening of both the post and the root dentin has been shown to increase the interfacial bond strength of the luting system by combining chemical bonding with micromechanical retention [25].

Even though no complete root fracture was observed after chewing simulation, there were significant differences in the incidence of dentin defects. The second null hypothesis was therefore rejected. Adhesive luting of FRC posts reduced the risk of dentin defects, while zinc phosphate cemented FRC posts caused the highest incidence of vertical cracks. Although adhesive luting of FRC posts is mandatory, variations in bond quality, due, for example, to the bonding procedure, could therefore influence the incidence of vertical cracks and future root fractures. In general, vertical cracks in the study caused lower VRF resistance $(760 \pm 265 \mathrm{~N}, \mathrm{n}=34)$ than craze lines $(936 \pm 318 \mathrm{~N}, \mathrm{n}=29)$. Fatigue analyses of FRC post-restored teeth showed that adhesive failure of the coronal composite filling increases the dentin stress at the cavity floor, which can lead to VRF [26]. 3D-FEM analyses of postrestored teeth demonstrated that zinc phosphate cemented or adhesively failed FRC posts generated higher stress in root dentin than metal posts $[18,19]$. The latter also indicated that roots restored with FRC posts are less prone to fracture because the fracture risk of the FRC post and the composite core build-up was higher than that of the root [19]. The present test setup avoided any direct contact with the post. The posts were not evaluated as a retainer for the coronal restoration to assess a possible internal reinforcement of the root and exclude confounding factors such as post and core build-up fracture [21]. Many studies performed fracture resistance measurements and analyses on root canal-treated or postrestored teeth that had been decoronated $[5,6,13,21]$. From a clinical perspective, however, the results should be interpreted with caution since a coronal restoration could lead to a more favorable stress distribution. External reinforcement of the root was avoided by using a thin latex milk layer as a simulated periodontal ligament.

In preliminary tests for the study, the external root surfaces were examined for dentin defects after root canal filling, and no damage was found. An explanation is that possible dentin defects that could be initiated during root canal instrumentation and filling progressed within the inner core dentin adjacent to the root canal wall and were therefore not detectable on the external root surface. Nickel-titanium files with a smaller file taper (4\%) were used, as larger file tapers have been shown to reduce the VRF resistance of root canal-filled teeth [5]. In addition, studies showed that single-cone filling techniques like the one used in this study reduce the incidence of dentin defects compared to lateral compaction of gutta percha $[4,5]$. The incidence of dentin defects increased with post space preparation as the root canal wall is further reduced and the inner core dentin with a lower Young's modulus than the more mineralized outer dentin is removed $[4,6,27]$. 
Regardless of the post group, most dentin defects were observed in the cervical two thirds of the root samples. The lower incidence of apical defects is consistent with clinical observations in post-restored teeth [28]. The post space was not prepared into the apical third. Since the tubular density in the root canal decreases from cervical to apical, there are also fewer dentin tubules in the apical part from which cracks can initiate. Morphological examinations on root-filled teeth have provided some evidence that the presence and orientation of dentin tubules influence the crack initiation in root dentin [29]. Cracks were initiated in the peritubular dentin of individual tubules and progressed through the intertubular collagen matrix surrounding the tubules [29]. Fatigue analyses showed that peritubular dentin is more mineralized than intertubular dentin, more brittle and easier to crack [20]. Due to the higher tubule density of the cervical and middle root third, the cracks may have propagated more frequently through the tubules than in the dentin bulk of the apical root third [20].

The prospective power analysis indicated that significant results can be achieved with a sample size of $n$ $=18$ per group. Although attempts were made to standardize the roots in terms of dimension, length and cross-sectional anatomy as well as sample preparation, the coefficient of variation of VRF resistance was between $28-36 \%$. This has been reported as a common finding in fracture load testing and to some extent reflects differences in age, dentin microstructure, and morphology between extracted human teeth [21].

\section{Conclusions}

Within the limitations of this study, it can be concluded that the incidence of dentin defects is higher for post-restored roots than for untreated teeth. Adhesively luted FRC posts did not increase the vertical root fracture resistance but reduced the risk of dentin defects. Most dentin defects were craze lines and vertical root cracks.

\section{Declarations}

\section{Acknowledgements:}

The authors are grateful to Prof. Rainer Muche, Institute of Biometry, University of Ulm for the statistical analysis. Beatrice Hrusa carried out the experiments in partial fulfilment of her doctoral degree. The authors thank Prof. Bernd Haller, Center of Oral Health, University of Ulm for supervising her doctoral thesis. The authors thank Brasseler Komet for providing the post-luting systems.

\section{Conflict of interest:}

Author Henry Frehse declares that he has no conflict of interest. Author Beatrice Hrusa declares that she has no conflict of interest. Author Andreas Rathke is an employee of Dentsply Sirona in Konstanz.

\section{Ethical approval:}


This article does not contain any studies with human participants or animals performed by any of the authors.

\section{References}

1. Haueisen H, Gärtner K, Kaiser L, Trohorsch D, Heidemann D. Vertical root fracture: prevalence, etiology, and diagnosis. Quintenssence Int. 2013;44:467-74.

2. Yoshino K, Ito K, Kuroda M, Sugihara N. Prevalence of vertical root fracture as the reason for tooth extraction in dental clinics. Clin Oral Investig. 2015;19:1405-9.

3. Maddalone M, Gagliani M, Citterio CL, Karanxha L, Pellegatta A, Del Fabbro M. Prevalence of vertical root fractures in teeth planned for apical surgery. A retrospective cohort study. Int Endod J. 2018;51:622-7.

4. Çapar ID, Uysal B, Ok E, Arslan H. Effect of the size of the apical enlargement with rotary instruments, single-cone filling, post space preparation with drills, fiber post removal, and root canal filling removal on apical crack initiation and propagation. J Endod. 2015;41:253-6.

5. Lin GSS, Singbal KP, Noorani TY, Penukonda R. Vertical root fracture resistance and dentinal crack formation of roor canal-treated teeth instrumented with different nickel-titanium rotary systems: an in-viro study. Odontology. 2021 Jul 16. doi: 10.1007/s10266-021-00643-y. Online ahead of print.

6. Mireku AS, Romberg E, Fouad AF, Arola D. Vertical fracture of root filled teeth restored with posts: the effects of patient age and dentine thickness. Int Endod J. 2010;43:218-25.

7. Goracci C, Ferrari M. Current perspectives on post systems: a literature review. Aust Dent J. 2011;56:77-83.

8. Guldener KA, Lanzrein CL, Guldener BE, Lang NP, Ramseier CA, Salvi GE. Long-term clinical outcomes of endodontically treated teeth restored with or without fiber post-retained single-unit restorations. $J$ Endod. 2017;43:188-93.

9. Küçük Ö, Keçeci AD. Strengthening effect of different fiber placement designs on root canal treated and bleached premolars. Odontology. 2021;109:349-57.

10. Fráter M, Sáry T, Néma V, Braunitzer G, Vallittu P, Lassila L, Garoushi S. Fatigue failure load of immature anterior teeth: influence of different fiber-post-core systems. Odontology. 2021;109:22230.

11. Zhou L, Wang Q. Comparison of fracture resistance between cast posts and fiber posts: a metaanalysis of literature. J Endod. 2013;39:11-5.

12. Wang X, Shu X, Zhang Y, Yang B, Jian Y, Zhao K. Evaluation of fiber posts vs metal posts for restoring severely damaged endodontically treated teeth: a systematic review and meta-analysis. Quintessence Int. 2019;50:8-20.

13. Sagsen B, Zortuk M, Ertas H, Er O, Demirbuga S, Arslan H. In vitro fracture resistance of endodontically treated roots filled with a bonded filling material or different types of posts. $J$ Endod. 2013;39:1435-7. 
14. Josic U, Radovic I, Juloski J, Beloica M, Popovic M, Alil A, Mandic J. Can fiber-post placement reinforce structurally compromised roots? J Adhes Dent. 2020;22:409-14.

15. Davies H, Ahmed SH, Edwards D. Metal vs fibre posts - which is clinically superior for the restoration of endodontically treated teeth? Evid Based Dent. 2021;22:162-63.

16. Naumann M, Sterzenbach G, Dietrich T, Bitter K, Frankenberger R, von Stein-Lausnitz M. Dentin-like versus rigid endodontic post: 11-year randomized controlled pilot trial on no-wall to 2-wall defects. J Endod. 2017;43:1770-5.

17. Brignardello-Petersen R. Insufficient evidence about long-term success of glass-fiber versus titanium posts in severely damaged teeth owing to large proportion of participant lost to follow-up in a randomized clinical trial. J Am Dent Assoc. 2018;149:e36.

18. Romeed SA, Dunne SM. Stress analysis of different post-luting systems: a three-dimensional finite element analysis. Aust Dent J. 2013;58:82-8.

19. Santos AF, Meira JB, Tanaka CB, Xavier TA, Ballester RY, Lima RG, Pfeifer CS, Versluis A. Can fiber posts increase root stresses and reduce fracture? J Dent Res. 2010;89:587-91.

20. Arola D, Reprogel RK. Effects of aging on the mechanical behavior of human dentin. Biomaterials. 2005;26:4051-61.

21. Naumann M, Metzdorf G, Fokkinga W, Watzke R, Sterzenbach G, Bayne S, Rosentritt M. Influence of test parameters in in vitro fracture resistance of post-endodontic restorations: a structured review. $J$ Oral Rehabil. 2009;36:299-312.

22. Serino G, Comba A, Baldi A, Carossa M, Baldissara P, Bignardi C, Audenino A, Torres CGR, Scotti N. Could light-curing time, post-space region and cyclic fatigue affect the nanomechanical behavior of a dual-curing cement for fiber-post luting? J Mech Behav Biomed Mater. 2022;Jan;125:104886.

23. Ubaldini ALM, Benetti AR, Sato F, Pascotto RC, Medina Neto A, Baesso ML, Peutzfeldt A. Challenges in luting fibre posts: adhesion to the post and to the dentine. Dent Mater. 2018;34:1054-62.

24. Rathke A, Frehse H, Muche R, Haller B. Durability of fiber post-to-composite bonds achieved by physical vapor deposition and tribochemical silica coating. J Adhes Dent. 2014;16:559-65.

25. Nergiz I, Schmage P. ER System: Erlanger Wurzelstift-Aufbausystem. Brasseler Komet. 2009;8:1-29.

26. Lin F, Ordinola-Zapata R, Ye N, Xu H, Fok ASL. Fatigue analysis of restored teeth longitudinally cracked under cyclic loading. Dent Mater. 2021 Dec 20;S0109 5641(21)00340-7. doi: 10.1016/j.dental.2021.12.005. Online ahead of print.

27. Kishen A, Kumar GV, Chen NN. Stress-strain response in human dentine: rethinking fracture predilection in postcore restored teeth. Dent Traumatol. 2004;20:90-100.

28. Sugaya T, Nakatsuka M, Inoue K, Tanaka S, Miyaji H, Sakagami R, Kawamami M. Comparison of fracture sites and post lengths in longitudinal root fractures. J Endod. 2015;41:159-63.

29. Jainaen A, Palamara JEA, Messer HH. Effect of dentinal tubules and resin-based endodontic sealers on fracture properties of root dentin. Dent Mater. 2009;25:e73-81. 


\section{Table 1}

Table 1 Mean and standard deviation of VRF resistance $(\mathrm{N})$ and cross-sectional area $\left(\mathrm{mm}^{2}\right)$ as well as the incidence of dentin defects (absolute number) of the different groups.

\begin{tabular}{|c|c|c|c|c|c|c|c|}
\hline \multirow[b]{2}{*}{ Group } & \multirow[b]{2}{*}{$\mathrm{n}$} & \multirow[b]{2}{*}{$\begin{array}{l}\text { VRF resistance } \\
(\mathrm{N})\end{array}$} & \multirow[b]{2}{*}{$\begin{array}{l}\text { Area } \\
\left(\mathrm{mm}^{2}\right)\end{array}$} & \multirow[b]{2}{*}{$\begin{array}{l}\text { no } \\
\text { defect }\end{array}$} & \multicolumn{3}{|c|}{ Dentin defect } \\
\hline & & & & & $\begin{array}{l}\text { craze } \\
\text { line }\end{array}$ & $\begin{array}{l}\text { vertical } \\
\text { crack }\end{array}$ & $\begin{array}{l}\text { horizontal } \\
\text { crack }\end{array}$ \\
\hline Control & 18 & $750.4 \pm 214.3$ & $\begin{array}{l}20.46 \pm \\
2.57\end{array}$ & 12 & 3 & 3 & 0 \\
\hline TIT/C & 18 & $920.8 \pm 327.7$ & $\begin{array}{l}20.95 \pm \\
2.62\end{array}$ & 3 & 9 & 6 & 0 \\
\hline TIT/A & 18 & $863.6 \pm 311.2$ & $\begin{array}{l}22.19 \pm \\
3.83\end{array}$ & 3 & 6 & 8 & 1 \\
\hline $\mathrm{FRC} / \mathrm{C}$ & 18 & $748.1 \pm 238.8$ & $\begin{array}{l}20.35 \pm \\
2.93\end{array}$ & 2 & 4 & 12 & 0 \\
\hline $\mathrm{FRC} / \mathrm{A}$ & 18 & $866.4 \pm 304.6$ & $\begin{array}{l}20.54 \pm \\
2.03\end{array}$ & 6 & 7 & 5 & 0 \\
\hline Total & 90 & $829.9 \pm 285.1$ & $\begin{array}{l}20.94 \pm \\
2.89\end{array}$ & 26 & 29 & 34 & 1 \\
\hline
\end{tabular}

$\mathrm{A}=$ adhesive luting; $\mathrm{C}=$ cementation; $\mathrm{FRC}=$ coated glass fiber-reinforced composite post; $\mathrm{TIT}=$ sandblasted titanium post; VRF = vertical root fracture. No significant differences between the groups regarding VRF resistance $(P=0.265)$ and cross-sectional area $(P=0.402)$.

\section{Figures}




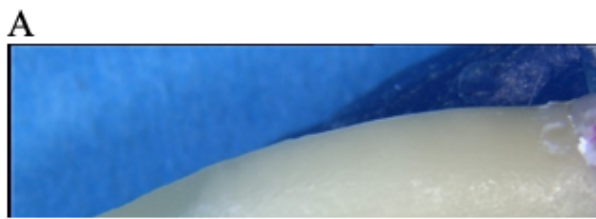

\section{Figure 1}

Representative images of the different dentin defects along the root surface after chewing simulation. A, no defect. B, craze line. C, vertical crack. D, horizontal crack. Original magnification $\times 12$ in each case. 